\title{
Libraries Helping Faculty: A New Information Literacy Tool Is Quickly Adopted
}

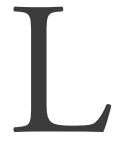
ibrary instruction has been an academic library staple since almost the beginning of the profession in the nineteenth century. Originally termed 'bibliographic instruction' the familiar 'BI,' was centered on the use of printed materials to deliver content. Over the past two decades, the focus of instruction has evolved from the original purpose of learning to use the library to find information. Now Information Literacy (IL) has become the key instruction activity for the library, and the standard model of promoting the library through instruction at the beginning of each academic semester. This refocused instruction activity is directed toward evaluating information, especially information found online, but also what is found in the various electronic resources available through subscription from content aggregators.

\section{Bibliographic Instruction at Queens University of Charlotte}

This is the path along which BI evolved at Everett Library at Queens University of Charlotte. As a smaller academic library with limited resources, staff at Everett pride themselves on providing excellent service including instruction. This extends to IL, and Everett also began to incorporate IL into its core instruction program aligned first to Association of College \& Research Libraries Information Literacy Competency Standards for Higher Education, and later to the updated ACRL Information Literacy and to Common Core English Language Arts standards. As other libraries began to develop online tutorials in IL, Everett Library did so as well, creating its own very basic tutorials beginning in 2012.

However, there were challenges. Homegrown tutorials sometimes mean uneven presentation of information, limited graphics, and don't always tap into college-age student expectations or attention spans. Testing protocols developed locally meant the entire IL program needed to be viewed in order to complete it and there was not a way to access the program otherwise. For example, it was not possible to extract a lesson on creating citations without starting from the beginning of the program. In 2015 the library determined that a different approach was needed. Understanding that library staff lacked the skill set of instructional design or web developer, it made sense to look at proprietary offerings from academic library providers.

It was clear that tutorials were the best way to meet student IL needs. While they do not connect face to face with students like the traditional BI class, online tutorials offer a clear advantage over the old BI and IL model of a class or two in the library at the beginning of the semester. An online tutorial can be accessed at any time and can be viewed multiple times so that when students start to begin research projects, which often happens well into the academic semester, they can go back and review information from the IL tutorials to remind them of best practices and research skills.

During the summer of 2015, in evaluating alternatives, Everett Library focused on two commercial products in order to simplify the selection process. After contacting the vendors, trials of the products were arranged. The evaluation process was important, as not only were the products useful for the library but also were seen to have applications in the Center for Student Success, Haworth School for Adult Education, and the Center for the Advancement of Faculty Excellence. During the trial period, feedback was solicited and received from faculty members in those departments that focused on testing the product, connecting to current applications for which the product would bring improved outcomes, and seeking other uses for the product within services the departments currently provide. At the library, during the trial period, the products were evaluated using these criteria: measuring the operability of the products against each other, comparing them to the current tools that had previously been created in-house, and determining the best value of the two offers. Best value determination means that the lowest price is not the primary driver even though it will certainly factor into the final decision. In a best value scenario, all qualities of a given product are accessed before price is added to the equation. In this way the cheapest does not always win because it is not necessarily the best.

With all input received, a purchase decision was made in September 2015 and communicated to everyone who participated in the process. Given the product is electronic software, actual receipt of the product was rather swift. What remained was to integrate the new software into the library website and roll it out to faculty and staff. One of the first tasks before introducing the new IL tool to faculty and students 
was to think about the applications of how it would be used and introduced to the wider campus community. First, librarians needed to learn all about the new tool and develop a comfort level with navigating around the website before rolling it out. It was important to see all of the functions of the tool and to watch the large assortment of videos that were available. Developing ideas of how to incorporate the new IL tool within the library website was necessary since it was going to take the place of the outdated IL tool that was currently available. This work was valuable because a smooth rollout was desirable since change can be difficult and comfort plus confidence with the change was an optimal outcome. The new product was called Research Companion (RC).

\section{Rolling Out a New Library Tool to Faculty and Students}

Introducing $\mathrm{RC}$ to faculty was high on the priority of the library in the early stages of the rollout of the tool. Since the IL tool was something new and faculty were accustomed to the previous set of tutorials that was already imbedded into their curriculum, it was important to think about their concerns in making the change. The rollout process began in November 2015 at a meeting the Director of CAFÉ (Center for the Advancement of Faculty Excellence) to highlight usability and functionality of the tool for faculty and students with a specific focus on improved efficiency for faculty. The director offered to invite a small and diverse group of faculty from different academic disciplines to review the presentation for the new tool and help to promote its use. This consisted of a presentation on why the library was making a change, a functional demonstration of the tool, and questions about use from faculty. In Winter 2016 there was a presentation to the Library Advisory Committee, made up of faculty, staff and students, to publicize and demonstrate usability. Reactions and suggestions were noted. The final stage of the roll out in Spring 2016 was presenting RC to faculty at a regularly scheduled fullfaculty meeting. While being part of a larger agenda made the rollout somewhat time-restricted, it did provide a venue for the library to introduce RC to faculty, present the clear superiority over the current IL tool, connect $\mathrm{RC}$ to the course management processes, and provide specific contact information for library support and assistance in using RC in their classes.

An active demonstration of the RC tool was important because of all of the functions that it has. Specifically the tool includes nine different learning modules with over 80 video tutorials. It allows faculty to engage students in research methods such as choosing and refining a research topic, evaluating and citing resources, constructing the paper for clarity, and a revision aid. With so many functions, it was important for faculty to know and understand them in order to communicate to students who would be using it how it would make them more efficient and improve their scholarship. Another part of the rollout was through a library web page specifically focused on describing and previewing $\mathrm{RC}$ with demonstrations of its attributes. The page shows the modules and videos that are used, and a list of tools with screen captures that show how it works. An additional web page shows how students can create an account in RC to track tutorial videos reviewed in the modules and manage learning. Finally, a quiz was created to assess students' knowledge of the RC tool and the importance of information literacy. In this way, faculty could use the tool as an assignment and measure proficiency.
The continuing promotion of $\mathrm{RC}$ was also important to raise and maintain awareness of the tool and its value, especially as the Fall 2016 semester began. This involved not only talking to faculty but also promoting it to students in the library and through a number of messaging avenues across campus. In the library, fliers and posters were printed and placed in high traffic areas to call attention and one of the monitor screens ran a demo of the tool. Social media was used to promote the tool. And some basic actions such as sending a bulk email to faculty, students and staff linking the importance of the tool with student success were also used. A soft rollout and promotion began in the spring, and was accelerated in the fall to get more students and faculty familiar with the tool. All throughout this time, the central message of the promotion was to promote the positive benefits of $\mathrm{RC}$ to faculty and students, send out email blasts, use social media, and pepper the library and campus with posters.

One of the main concerns that was expressed by the faculty was how to incorporate RC with the university's course management system (CMS). Many of these faculty members already had the other IL tool embedded in their CMS pages, including the quiz associated with it. A number of faculty were accustomed to the other tool and its functionality. It became important to demonstrate that RC can be embedded easily into the CMS and that the quiz that was created can be associated with an assignment to students for showing proficiency in finding, evaluating and using information. In several meetings with faculty members, one of the biggest selling points for RC was that all the videos, or any specific ones, could be embedded in their CMS pages. It is a versatile function and something the faculty found to be important. On the library page 
describing RC, it was easy for students and faculty to find the tool even if it was not added to the CMS by the faculty. This meant anyone could use it, whether or not it was associated with a specific course, and could be promoted by the library directly to students in IL and BI classes.

A major factor that needed to be addressed was the quiz. The existing IL tool had a built-in quiz which was popular with faculty members and they did not want to lose that functionality. The version of RC added to library resources did not have a quiz, so it was upon the library to come up with questions and a platform to create a quiz. Two librarians and the instructional designer worked with the existing CMS quiz function to create a workable evaluation tool in the form of a quiz. It provided an opportunity for students to learn about the research process at their own pace, and was broken down into three sections: finding, evaluating, and using information. Students taking the quiz have to earn a certain grade demonstrating proficiency and then are given a certificate upon completion. This added functionality provides a way for faculty to have their students learn about the IL process and then to measure that learning either as a homework assignment using the quiz or demonstrated in a research paper.

\section{Assessing the Rollout and Ongoing Value}

Since the initial rollout of RC that began in late 2015, use of the tool has grown among faculty over eighteen months. Many newer faculty have added it to their CMS, while a few long-term faculty still prefer the previous tool (for now). The library continues to promote $\mathrm{RC}$ to students in all BI training sessions and on the website. Overall the rollout is considered a success with additional faculty integrating the tool into their CMS and teaching approaches. Use of RC has allowed students to become more autonomous in the learning process by allowing them to watch the videos and learn on their own pace, and the option for offering a quiz was found to be important in faculty adoption of the tool. RC provides the library with a platform to show students how to better locate, evaluate, and understand information they need for research. The quiz helps students learn and gain knowledge as well. RC training videos have become useful in classroom instruction and backs up what is taught in library instruction sessions. In addition, availability and use of RC videos and research tools by students and faculty have allowed the library staff to focus more on subject specific library instruction sessions. In all, library academic support for students and faculty has increased dramatically.

\section{Bibliography}

ACRL Information Literacy Competency Standards for Higher Education, http://www.ala.org/acrl/standards/informationliteracycompetency Accessed May 2017.

ACRL Information Literacy Framework, http://www.ala.org/acrl/standards/ilframework accessed May 2017.

Common Core Language Arts Standards, http://www.corestandards.org/ELALiteracy/ Accessed May 2017.

Research Companion at Everett Library, Queens University of Charlotte, http:// library.queens.edu/researchcompanion Accessed May 2017.

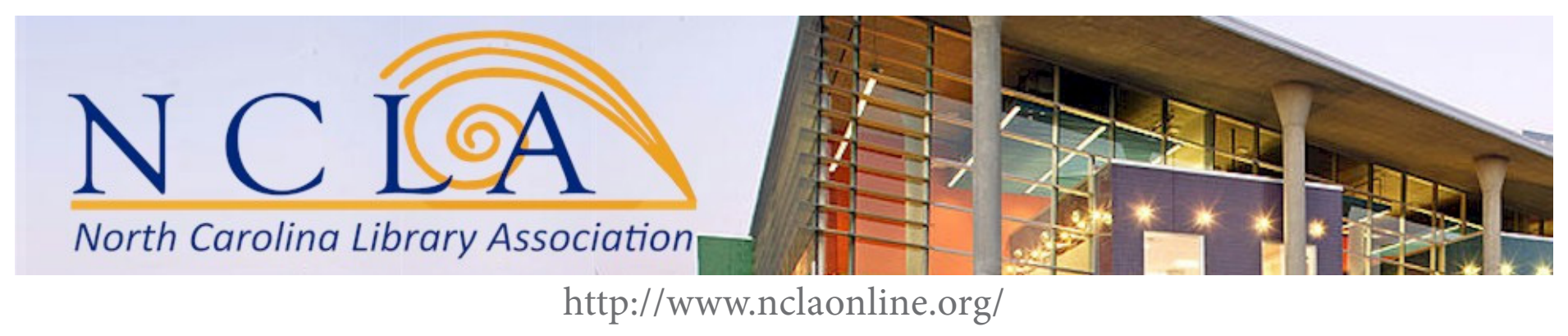

